\title{
Environmental Fate of Triasulfuron in Soils Amended with Municipal Waste Compost
}

\author{
Daniel Said-Pullicino, Giovanni Gigliotti,* and Alfred J. Vella
}

\begin{abstract}
The amendment of soil with compost may significantly influence the mobility and persistence of pesticides and thus affect their environmental fate. Factors like adsorption, kinetics, and rate of degradation of pesticides could be altered in amended soils. The aim of this study was to determine the effects of the addition of compost made from source-separated municipal waste and green waste, on the fate of triasulfuron [(2-(2-chloroethoxy)- $N$-[[4-methoxy-6-methyl-1,3,5-triazin2-yl)amino]carbonyl]benzenesulfonamide], a sulfonylurea herbicide used in postemergence treatment of cereals. Two native soils with low organic matter content were used. A series of analyses was performed to evaluate the adsorption and degradation of the herbicide in soil and in solution after the addition of compost and compostextracted organic fractions, namely humic acids (HA), fulvic acids (FA), and hydrophobic dissolved organic matter (HoDOM). Results have shown that the adsorption of triasulfuron to soil increases in the presence of compost, and that the HA and HoDOM fractions are mainly responsible for this increase. Hydrophobic dissolved organic matter applied to the soils underwent sorption reactions with the soils, and in the sorbed state, served to increase the adsorption capacity of the soil for triasulfuron. The rate of hydrolysis of triasulfuron in solution was significantly higher at acidic $\mathrm{pH}$ and the presence of organic matter fractions extracted from compost also slightly increased the rate of hydrolysis. The rate of degradation in amended and nonamended soils is explained by a two-stage degradation kinetics. During the initial phase, although triasulfuron degradation was rapid with a half-life of approximately $30 \mathrm{~d}$, the presence of compost and HoDOM was found to slightly reduce the rate of degradation with respect to that in nonamended soil.
\end{abstract}

$T$ HE USE OF COMPOST derived from source-separated municipal solid waste as a soil amender is now a common agronomic practice throughout the world. Such organic amendment serves to improve the physical and chemical soil properties, such as soil structure, waterholding capacity, and organic matter (OM) content and composition as well as soil fertility (Celis et al., 1998a, 1998b; Giusquiani et al., 1995). Recently, increased interest has been directed to the consequences of compost and other exogenous sources of organic $\mathrm{C}$ on the behavior of pesticides in soils (Barriuso et al., 1997; Businelli et al., 1998; Celis et al., 1998a, 1998b; Cox et al., 2001; Gigliotti and Solomon, 2000; Huang and Lee, 2001; Moorman et al., 2001; Senesi et al., 1997; Seol and Lee, 2000). The efficiency of herbicides and their bioavailability, as well as their recalcitrance and potential to act as environmental contaminants, partly depends on their retention and degradation on soil constituents. For this

D. Said-Pullicino and A.J. Vella, Department of Chemistry, University of Malta, Msida MSD06, Malta. G. Gigliotti, Dipartimento di Scienze Agroambientali e della Produzione Vegetale, University of Perugia, Borgo XX Giugno, 72, Perugia 06121, Italy. Received 4 Aug. 2003. *Corresponding author (gigliott@unipg.it).

Published in J. Environ. Qual. 33:1743-1751 (2004).

(c) ASA, CSSA, SSSA

677 S. Segoe Rd., Madison, WI 53711 USA reason the fate of a pesticide in soil can be determined by the complex interactions between the intrinsic properties of the pesticide, soil properties that define the medium containing the pesticide, and climate that determines temperature, water, and air fluxes.

The environmental fate of pesticides in soil may be greatly influenced by compost application because this practice increases the soil OM content and OM is reportedly a major component in the sorption, transformation, and transport of many organic pollutants in soil (Barriuso et al., 1997; Cox et al., 2001). Specifically, pesticide sorption has been shown to increase by organic amendment addition to soil (Barriuso et al., 1997; Businelli et al., 1998; Celis et al., 1998a, 1998b; Cox et al., 2001; Gigliotti and Solomon, 2000), mainly due to the high sorptive capacity of the added insoluble OM (Celis et al., 1998a; Cox et al., 2001). However, organic amendment can also produce dissolved organic matter (DOM) whose effect on pesticide sorption is far less understood (Celis et al., 1998a). Dissolved organic matter may reduce pesticide sorption through stable DOM-pesticide interactions in solution or by competing with pesticide molecules for sorption sites on the soil surface (Celis et al., 1998a, 1998b; Huang and Lee, 2001). However, it may also enhance pesticide sorption if the DOM sorbed on soil particles provides additional sites for pesticide sorption (Businelli et al., 1998). The overall effect of both insoluble and soluble OM on pesticide sorptiondesorption is not easy to predict. Apart from soil characteristics and the chemical nature of the pesticide, size, polarity, and molecular configuration of the OM determine its effectiveness in interacting with soils and pesticides (Celis et al., 1998b).

The addition of organic amenders to soils normally results in an increase in the microbiological activity due to the availability of simple organic molecules such as sugars, amino sugars, and amino acids. This increase in microbial activity cannot be directly related to an increase in the rate of degradation of pesticides in amended soils. In some cases soil amendment has led to a decrease in the half-life of a pesticide while in others an increase or even no effect was noted (Businelli et al., 1998; Cox et al., 2001; Moorman et al., 2001).

Triasulfuron is a selective sulfonylurea herbicide used at very low application rates $\left(10-40 \mathrm{~g}\right.$ a.i. ha $\left.{ }^{-1}\right)$ for weed control in cereals. Most sulfonylurea herbicides (including triasulfuron) exhibit low mammalian toxicity; however, because of their high potency as herbicides and long persistence in some soils, concerns have been expressed about their residual effects in soil and on crops (Braschi et al., 1997; Dinelli et al., 1998; Sarmah et

Abbreviations: DOM, dissolved organic matter; FA, fulvic acids; HA, humic acids; HoDOM, hydrophobic dissolved organic matter; HPLC, high performance liquid chromatography; MWC, municipal waste compost; OM, organic matter. 
Table 1. Some chemical and physical properties of the soils.

\begin{tabular}{lccccccc}
\hline Soil & pH & Sand & Silt & Clay & OC $\dagger$ & $\begin{array}{c}\text { Maximum field } \\
\text { capacity }\end{array}$ \\
\hline & & \multicolumn{4}{c}{$\mathbf{g ~ k g}^{-1}$} & & $\%$ \\
$\begin{array}{l}\text { Molinaccio } \\
\text { (clay loam soil) }\end{array}$ & 8.0 & 200 & 470 & 330 & 14.1 & 36.8 \\
Filoncia (loam soil) & 8.3 & 310 & 490 & 200 & 8.6 & 32.4
\end{tabular}

$\dagger$ Organic carbon content.

al., 2000). The most important pathways of triasulfuron dissipation in soils are chemical hydrolysis and microbial breakdown. Chemical hydrolysis involves the cleavage of the sulfonylurea bridge to form a sulfonamide, an aminoheterocycle, and carbon dioxide, making the molecule biologically inactive. Microbial breakdown involves the metabolism of the herbicide in soil, ultimately resulting in complete mineralization of the chemical. Although numerous studies have been performed to evaluate the fate of triasulfuron in soil, they usually focused on determination of its retention and degradation as a function of soil characteristics (Braschi et al., 1997; Dinelli et al., 1998; Pizzigallo et al., 2001; Sarmah et al., 2000). However, little information is available on the effect of organic amendment on the fate of triasulfuron in soil.

The main objectives of this study were to investigate and understand the role of soil amendment by compost on the fate of triasulfuron in the soil environment. For this purpose, laboratory studies were designed to (i) examine the influence of the addition of compost and its humic-like fractions and hydrophobic dissolved organic matter (HoDOM) on the overall sorption of triasulfuron by the soil, (ii) investigate the adsorption of triasulfuron by HoDOM extracted from compost, (iii) determine the rate of hydrolysis of triasulfuron at different $\mathrm{pH}$ values in aqueous solutions containing humic-like fractions or HoDOM from compost, and (iv) determine the degradation rates of triasulfuron in microbially active, amended and nonamended soils.

\section{MATERIALS AND METHODS}

\section{Chemicals}

Triasulfuron (purity 95.0\%) was supplied by Dr. Ehrenstorfer GmbH (Augsburg, Germany) and used in all experiments. The compound was quoted to have a $\mathrm{pK}_{\mathrm{a}}$ of 4.5 in water (Braschi et al., 1997). All solvents were of high performance liquid chromatography (HPLC) grade (BDH Ltd., Poole, UK) and were used without further purification. All other reagents were of analytical grade (Carlo Erba Reagenti, Milan, Italy).

\section{Soils and Compost}

Two agricultural soils, a clay loam and a loam soil, with low OM content, typical of central Italy (Tiber Valley, Umbria), were collected and used throughout this work. The fresh soils were air-dried, crushed to pass through a $2-\mathrm{mm}$ sieve, and thoroughly mixed before use. The major chemical and physical properties of the soils are reported in Table 1.

Municipal waste compost (MWC) was collected from the composting plant in Perugia (Italy). The 120- $\mathrm{d}$ mature compost was produced mechanically under aerobic conditions by fast
Table 2. Characteristics of municipal waste compost.

\begin{tabular}{|c|c|}
\hline Characteristic & Value $\dagger$ \\
\hline Moisture content, $\mathbf{g ~ k g}^{-1}$ & $495 \pm 1$ \\
\hline Ash content, $\mathrm{g} \mathrm{kg}^{-1}$ & $357 \pm \mathbf{3}$ \\
\hline pH & $6.8 \pm 0.2$ \\
\hline Total organic carbon (OC), g OC kg-1 & $341 \pm 10$ \\
\hline Total extractable carbon, g OC kg-1 & $175 \pm 2$ \\
\hline Humic acids, ${\mathrm{g} \mathrm{OC} \mathrm{g}^{-1}}^{-1}$ & $132 \pm 7$ \\
\hline Fulvic acids, g OC $\mathrm{kg}^{-1}$ & $19 \pm 3$ \\
\hline Nonhumic fraction, $\mathrm{g} \mathrm{OC} \mathrm{kg}^{-1}$ & $24 \pm 2$ \\
\hline Dissolved organic carbon, g OC kg-1 & $10.8 \pm 0.1$ \\
\hline $\begin{array}{l}\text { Hydrophobic dissolved organic matter } \\
\text { (DOM), g OC kg-1 }\end{array}$ & $4.8 \pm 0.1$ \\
\hline Hydrophilic DOM, g OC kg-1 & $4.4 \pm 0.1$ \\
\hline
\end{tabular}

$\dagger$ Values are averages of duplicate analysis \pm standard errors; all data except moisture content are expressed on a dry-weight basis.

fermentation (25 d) from a 1:1 mixture of source-separated municipal solid waste and yard trimmings from pruning activities, followed by a 90-d maturation phase. A number of characteristics of the compost used are reported in Table 2. The fresh compost was air-dried, crushed to pass through a 2-mm sieve, and thoroughly mixed before use.

\section{Extraction and Fractionation of Compost Dissolved Organic Matter and Humic-Like Substances}

Dissolved organic matter was extracted from municipal waste compost and fractionated as described by Gigliotti et al. (2002). Fractionation of the DOM solution was performed on an Amberlite XAD-8 resin (Rohm and Hass, Philadelphia, PA). The lyophilized HoDOM was stored in a dry environment and used throughout this work.

Humic-like substances were extracted from municipal waste compost as described by Gigliotti et al. (1999). The alkaline extract was acidified to $\mathrm{pH} 2$ with $3 \mathrm{M} \mathrm{H}_{2} \mathrm{SO}_{4}$ and left to stand overnight. The fulvic acids (FA) were separated from the coagulated humic acids (HA) by centrifugation. The FA were purified from nonhumic substances (NHS) by passing through an Amberlite XAD-7 resin (Rohm and Hass). The effluent was discarded and the FA were first eluted with $0.1 M \mathrm{NaOH}$ and then passed through an AG MP-50, 100-200 mesh, strongly acidic cation exchange resin (BioRad, Richmond, VA) to obtain purified $\mathrm{H}^{+}$saturated FA. The sample was then freeze-dried. The precipitated HA were dissolved in the minimum amount of $0.1 \mathrm{M} \mathrm{KOH}$ and reprecipitated with $6 \mathrm{M} \mathrm{HCl}$, and the suspended solids were removed by centrifugation. The remaining $\mathrm{HA}$ were resuspended in $0.1 \mathrm{M} \mathrm{HCl}$, dialyzed in water, and freeze-dried. The lyophilized fulvic and humic acids extracts were stored in a dry environment and used throughout this work.

\section{Adsorption Studies with Amended and Nonamended Soils}

The adsorption isotherms of triasulfuron on soil, compostamended soil, as well as HoDOM-, FA-, and HA-treated soils were determined using the batch equilibrium method at $20^{\circ} \mathrm{C}$. Isotherms were obtained to describe the adsorption of triasulfuron on two soils with different OM content as well as amended with compost and with the various fractions of $\mathrm{OM}$ separated from compost. The compost was added to the soils at two application ratios of 30 and $90 \mathrm{Mg} \mathrm{ha}^{-1}$ expressed on a wet-weight basis. Hydrophobic dissolved organic matter, $\mathrm{HA}$, and FA were added to the two soils at an application ratio equivalent to $90 \mathrm{Mg} \mathrm{ha}^{-1}$ compost according to the percentage composition of the compost analyzed. In all cases a soil depth of $20 \mathrm{~cm}$ and a bulk density of $1.5 \mathrm{~kg} \mathrm{~L}^{-1}$ was assumed. All 
analyses including blank samples (without herbicide) were performed in duplicate.

Duplicate samples of $10 \mathrm{~g}$ (dry weight) of amended, treated, and nonamended soils were equilibrated in centrifuge tubes with $10 \mathrm{~mL}$ of herbicide solutions of concentrations $0.5,1.5$, 2.5, 3.5, and $4.5 \mu \mathrm{g} \mathrm{mL} \mathrm{m}^{-1}$. Calcium chloride $(0.005 M)$ was used as background electrolyte to minimize ionic strength changes and to promote clay flocculation. The $\mathrm{pH}$ of the samples during equilibration was similar to those reported for the respective soils (Table 1) and amendment with compost or treatment with the organic fractions did not significantly affect this value. After equilibration for $24 \mathrm{~h}$ the soil suspensions were centrifuged at $10000 \times g$ for $10 \mathrm{~min}$ and the supernatants filtered through a PTFE, $0.45-\mu \mathrm{m}$ membrane filter (Whatman, Maidstone, UK). Previously, it was established that equilibrium was reached within a $24-\mathrm{h}$ period and that no degradation or adsorption to the centrifuge tubes and membrane filter occurred. Equilibrium triasulfuron concentrations were determined in the supernatants by HPLC as described in "Analysis for Triasulfuron," below. The amounts sorbed were calculated from the difference between the initial and equilibrium concentrations of triasulfuron in solution and expressed on a dryweight basis. Adsorption isotherms were obtained by plotting the amount of herbicide adsorbed against the equilibrium concentration and the best fit through the points drawn by means of a nonlinear regression adapted for the Freundlich equation.

\section{Interaction between Pesticide and Dissolved Organic Matter}

The extent of interaction in solution between triasulfuron and HoDOM extracted from MWC was determined by an equilibrium dialysis technique. Spectral/Por 6 dialysis tubing (Spectrum Medical Industries, Houston, TX), with a molecular weight cutoff of $1000 \mathrm{Da}$, was washed repeatedly in distilled water. Aliquots $(20 \mathrm{~mL})$ of an aqueous solution containing $1.45 \mathrm{mg}$ OC $\mathrm{mL}^{-1}$ HoDOM, previously dialyzed through the same membrane to eliminate the portion of DOM $<1000 \mathrm{Da}$ possibly present, were transferred to dialysis tubing and placed into flasks containing $80 \mathrm{~mL}$ of aqueous solutions of triasulfuron having concentrations of $1.25,2.50,3.75,5.00$, and 6.25 $\mu \mathrm{g} \mathrm{mL}{ }^{-1}$. The flasks were equilibrated by shaking for $2 \mathrm{~d}$ at $20^{\circ} \mathrm{C}$. The $\mathrm{pH}$ of both solutions across the membrane was identical and did not change with equilibration time during dialysis. To verify that the dialysis membrane did not constitute a barrier to the passage of the herbicide and to verify that equilibrium was achieved, a solution of $5 \mu \mathrm{g} \mathrm{mL} \mathrm{m}^{-1}$ triasulfuron was dialyzed against distilled water. Pesticide concentrations inside and outside the dialysis tubing were determined by HPLC as described in "Analysis for Triasulfuron," below. Complete dissociation of the pesticide-DOM complex in the acetonitrile-water mobile phase during HPLC analysis was confirmed by comparing known pesticide concentrations in the presence and absence of DOM. The difference between pesticide concentrations inside and outside of the dialysis tubing was assumed to be the DOM-bound pesticide concentrations. All analyses were performed in duplicate. Sorption data were fitted into a nonlinear regression adapted for the Freundlich equation.

\section{Interaction between Dissolved Organic Matter and Soil}

The adsorption isotherms of HoDOM derived from MWC on the two soils were determined using the batch equilibrium method at $20^{\circ} \mathrm{C}$. Duplicate samples of $10 \mathrm{~g}$ (dry weight) of soil were equilibrated in centrifuge tubes with $10 \mathrm{~mL}$ of HoDOM solution having concentrations of $360,580,840$, and $1170 \mu \mathrm{g}$ OC $\mathrm{mL}^{-1}$ of $\mathrm{CaCl}_{2}(0.005 \mathrm{M})$. The $\mathrm{pH}$ of the suspensions during equilibration was similar to those reported for the respective soils (Table 1). After equilibration for $24 \mathrm{~h}$, the soil suspensions were centrifuged at $10000 \times g$ for $10 \mathrm{~min}$ and the supernatants filtered through a PTFE, $0.45-\mu \mathrm{m}$ membrane filter (Whatman). A blank was also performed for each soil sample to account for the desorption of soil-derived DOM. All analyses were performed in duplicate. Equilibrium HoDOM concentrations were measured in the supernatants using a UV spectrophotometer (Lambda EZ150; PerkinElmer, Wellesley, MA) by reading absorbance values at a wavelength of $330 \mathrm{~nm}$ (Moore, 1985) and correcting for the amount of DOM released by the soil alone. The amount of HoDOM sorbed was calculated from the difference between the initial and equilibrium concentrations and expressed on a dry-weight basis. Adsorption isotherms were obtained by plotting the amount of HoDOM adsorbed $\left(\mu \mathrm{g} \mathrm{OC} \mathrm{g}^{-1}\right)$ against free HoDOM in solution $\left(\mu \mathrm{g}\right.$ OC $\left.\mathrm{mL}^{-1}\right)$ and the best fit through the points drawn by means of a nonlinear regression adapted for the Freundlich equation.

\section{Hydrolysis Rate of Triasulfuron in Aqueous Solutions}

The hydrolysis rate of triasulfuron was determined by monitoring the disappearance of pesticide in aqueous solutions in the presence and absence of $\mathrm{OM}$ fractions extracted from MWC (i.e., HA, FA, and HoDOM) at $\mathrm{pH}$ values of 4.5 and 7.0. Aqueous solutions of triasulfuron with an initial concentration of $5 \mu \mathrm{g} \mathrm{mL}^{-1}$ were prepared in HPLC-grade water at $\mathrm{pH} 4.5$ and 7.0 using acetate and phosphate buffers, respectively. Some of the solutions also contained HA, FA, and HoDOM fractions extracted from compost at a concentration of $116 \mathrm{mg} \mathrm{OC} \mathrm{L}^{-1}$. The solutions were sterilized by filtration through a $0.2-\mu \mathrm{m}$ membrane filter (Whatman) to minimize microbial activity, and maintained in the dark at $20^{\circ} \mathrm{C}$. A $1-\mathrm{mL}$ aliquot of each test solution was sampled at various time intervals, treated with $10 \mu \mathrm{L}$ of a $50 \%$ solution of $\mathrm{H}_{3} \mathrm{PO}_{4}$, and immediately analyzed by HPLC. All analyses were performed in triplicate. Herbicide remaining was expressed as a percentage of the concentration before incubation (time zero). Halflives were determined by linear regression of the natural logarithm of the percentage of herbicide remaining against the time and the slope of each line.

\section{Degradation of Triasulfuron in Soils}

The rate of degradation of triasulfuron was determined by monitoring the disappearance of the herbicide in the two soil samples, in the presence and absence of compost and HoDOM. The experiment involved the use of three sets of containers containing 16 samples of $100 \mathrm{~g}$ dry weight of soil, soil amended with compost, and soil treated with HoDOM for each of the two soils under investigation. The compost was added to the soils at an application ratio of $30 \mathrm{Mg} \mathrm{ha}^{-1}$ while HoDOM was added at an application ratio equivalent to 90 $\mathrm{Mg} \mathrm{ha}^{-1}$ compost according to the percentage composition of the compost analyzed. In both cases a soil depth of $20 \mathrm{~cm}$ and a density of $1.5 \mathrm{~kg} \mathrm{~L}^{-1}$ was assumed.

Triasulfuron in HPLC-grade water was added to each container to give an initial triasulfuron concentration of $5.37 \mu \mathrm{g}$ per $100 \mathrm{~g}$ dry weight of amended or nonamended soil, equivalent to an application dose of $40 \mathrm{~g}$ active ingredient $\mathrm{ha}^{-1}$, assuming a soil depth of $5 \mathrm{~cm}$ and a bulk density of $1.5 \mathrm{~kg} \mathrm{~L}^{-1}$.

Soil moisture of the samples was adjusted to $75 \%$ of the field capacity by adding distilled water. The samples containing the 
(a)
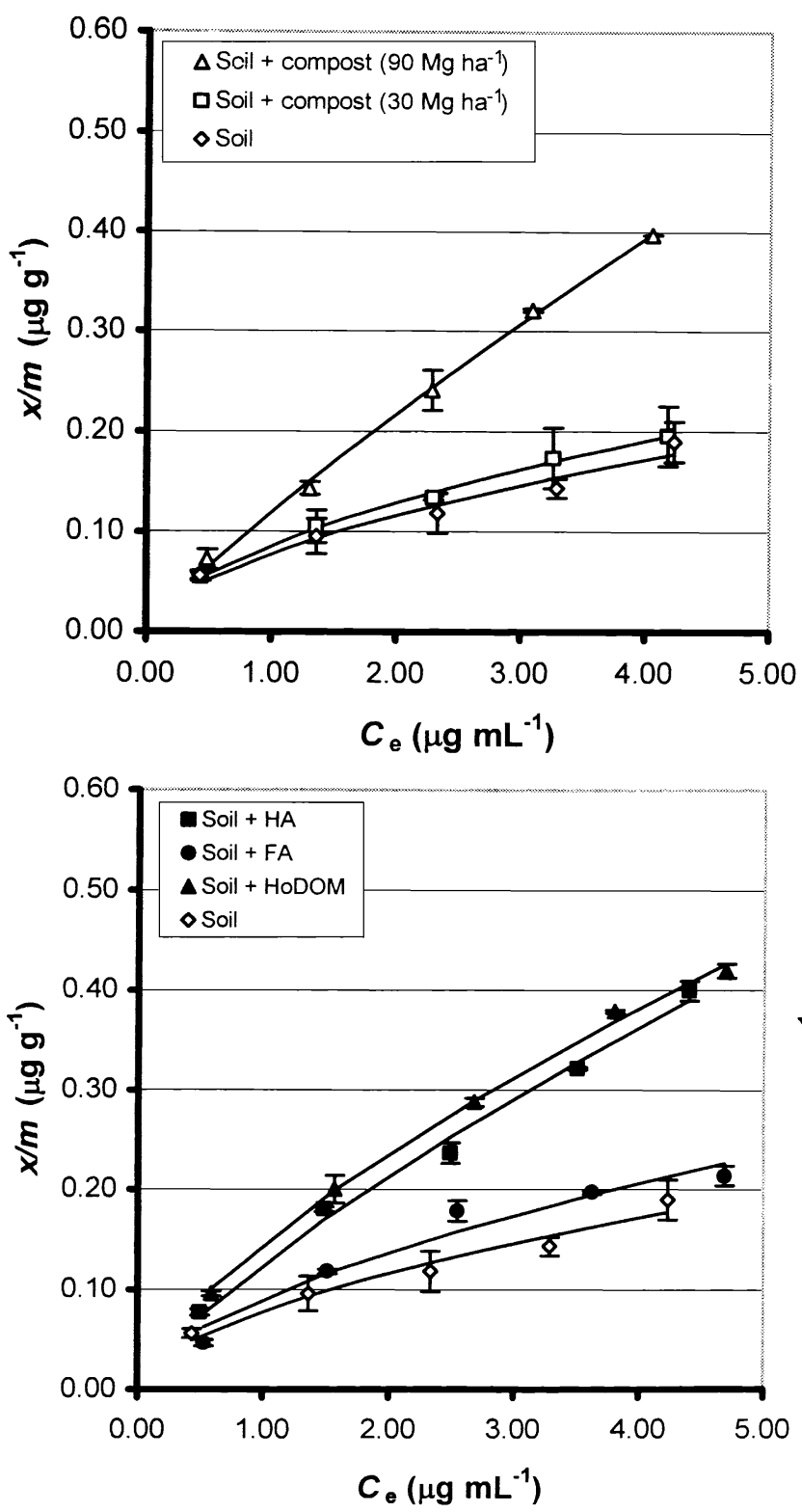

(b)
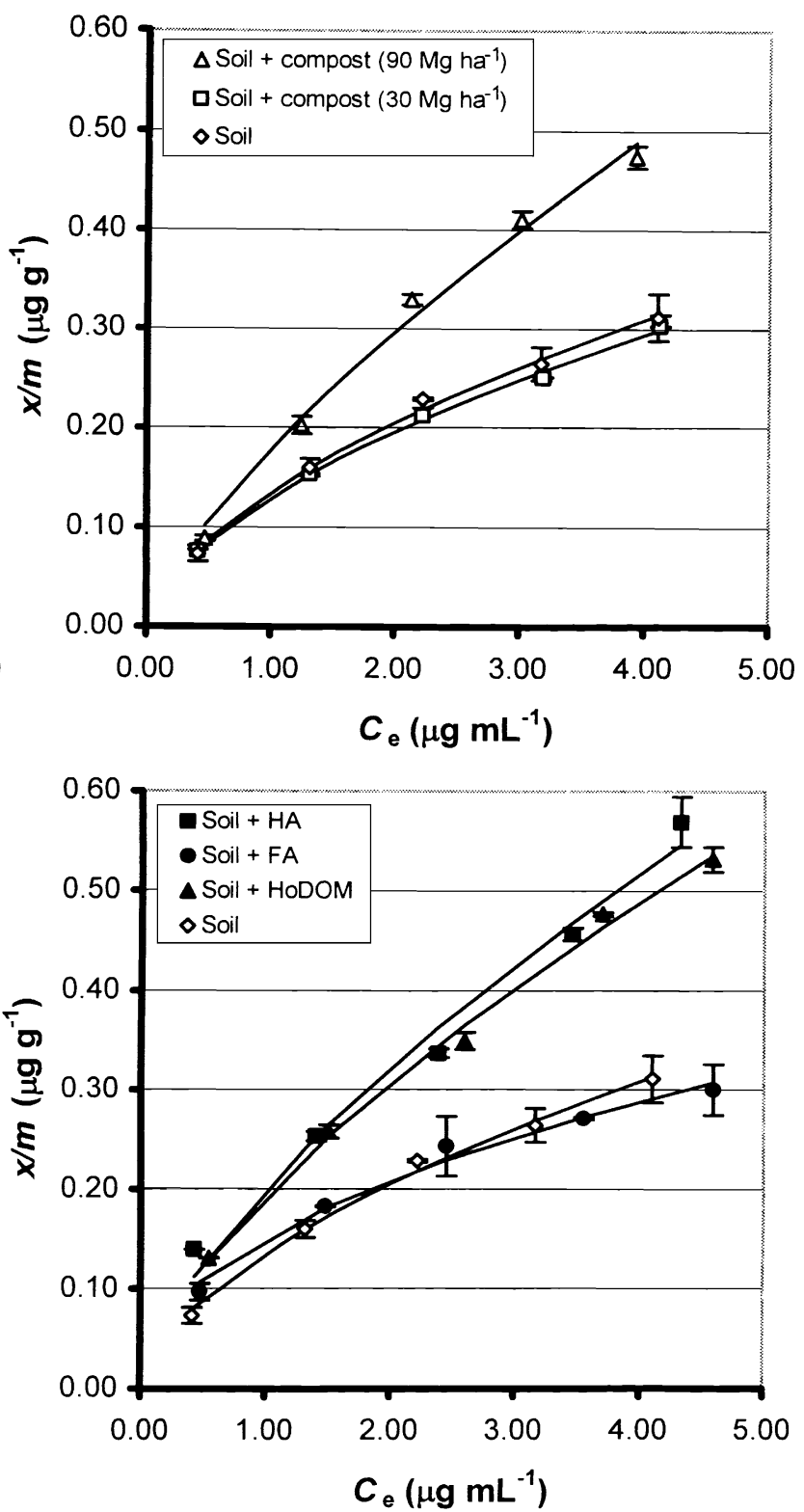

Fig. 1. Adsorption isotherms of triasulfuron on (a) Filoncia and (b) Molinaccio soils in the presence and absence of compost, humic acids (HA), fulvic acids (FA), and hydrophobic dissolved organic matter (HoDOM). Error bars represent SE.

treated, microbially active soil were kept in the dark in a climatic chamber at $20^{\circ} \mathrm{C}$. The moisture level of the soil samples was checked daily by weighing and adjusting as above. Two samples from each set were removed from the climatic chamber on Days $0,5,10,15,25,39,48$, and 62 and stored at $-20^{\circ} \mathrm{C}$ until extraction and analysis. All analyses were performed in duplicate.

Herbicide remaining was expressed as a percentage of concentration before incubation (time zero).

\section{Analysis for Triasulfuron}

Herbicide concentrations in solution were determined by HPLC using an HPLC system (PerkinElmer Series 200) with a variable wavelength UV/visible detector. The compounds were separated on a Spherisorb Octyl reverse-phase column $(250 \times 4.6 \mathrm{~mm}$, particle size $=5 \mu \mathrm{m}$; Sigma-Aldrich, St. Louis, MO). The mobile phase was a 40:60 mixture of acetonitrile and water adjusted to $\mathrm{pH} 2.5$ with $\mathrm{H}_{3} \mathrm{PO}_{4}$, at a flow rate of

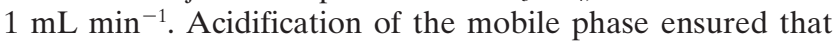
the sulfonylurea was in the neutral, undissociated form during the analysis. The UV detector was set at $223 \mathrm{~nm}$.

Herbicide standard solutions were prepared in acetonitrile from a $100 \mu \mathrm{g} \mathrm{mL} \mathrm{mL}^{-1}$ stock solution and stored at $4^{\circ} \mathrm{C}$ in the dark until use. The limit of quantification, estimated to be 10 times the background noise, was $0.1 \mu \mathrm{g} \mathrm{mL}{ }^{-1}$. No significant differences in background noise were observed between the analyses of the standards in acetonitrile and those of the sample matrices used. Therefore, the limits of quantification for 
Table 3. Freundlich constants and $K_{\mathrm{oc}}$ values for triasulfuron adsorption on amended and nonamended soils.

\begin{tabular}{|c|c|c|c|c|c|}
\hline Sorbent & Organic C & $K_{\mathbf{f}} \dagger$ & $1 / n \dagger$ & $r^{2}$ & $\boldsymbol{K}_{\mathrm{oc}} \dagger+$ \\
\hline & $\mathbf{g ~ k g}^{-1}$ & $\boldsymbol{\mu} \mathbf{g}^{(1-1 / n)} \mathbf{m} \mathbf{L}^{1 / n} \mathbf{g}^{-1}$ & \multicolumn{2}{|c|}{ _ dimensionless } & $\mu g^{(1-1 / n)} \mathbf{m L} L^{1 / n} g^{-1}$ \\
\hline Filoncia loam & 8.6 & $0.08 \pm 0.01$ & $0.56 \pm 0.08$ & 0.9613 & $9.2 \pm 0.9$ \\
\hline+ compost $\left(30 \mathrm{Mg} \mathrm{ha}^{-1}\right)$ & 12.0 & $0.09 \pm 0.01$ & $\mathbf{0 . 5 7} \pm \mathbf{0 . 0 3}$ & 0.9962 & $7.2 \pm 0.2$ \\
\hline+ compost $\left(90 \mathrm{Mg} \mathrm{ha}^{-1}\right)$ & 18.8 & $0.12 \pm 0.01$ & $0.86 \pm 0.03$ & 0.9976 & $6.4 \pm 0.3$ \\
\hline+ HoDOM (1.5 $\left.\mathrm{g} \mathrm{kg}^{-1}\right) \S$ & 9.5 & $0.15 \pm 0.01$ & $0.69 \pm 0.03$ & 0.9975 & $15.4 \pm 0.5$ \\
\hline+ HA $\left(7.4 \mathrm{~g} \mathrm{~kg}^{-1}\right) \S$ & 12.6 & $0.13 \pm 0.01$ & $0.76 \pm 0.06$ & 0.9918 & $10.0 \pm 0.7$ \\
\hline+ FA (1.1 g kg $\left.^{-1}\right) \S$ & 9.2 & $0.09 \pm 0.01$ & $\mathbf{0 . 5 8} \pm \mathbf{0 . 1 0}$ & 0.9551 & $\mathbf{1 0 . 0} \pm \mathbf{1 . 2}$ \\
\hline Molinaccio clay loam & 14.1 & $0.14 \pm 0.01$ & $\mathbf{0 . 5 9} \pm \mathbf{0 . 0 3}$ & 0.9944 & $9.6 \pm 0.4$ \\
\hline+ compost $\left(30 \mathrm{Mg} \mathrm{ha}^{-1}\right)$ & $\mathbf{1 7 . 5}$ & $0.13 \pm 0.01$ & $0.59 \pm 0.02$ & 0.9974 & $7.5 \pm 0.2$ \\
\hline+ compost $\left(90 \mathrm{Mg} \mathrm{ha}^{-1}\right)$ & 24.3 & $0.18 \pm 0.01$ & $0.74 \pm 0.05$ & 0.9911 & $7.3 \pm 0.5$ \\
\hline + HoDOM (1.5 g kg $\left.{ }^{-1}\right) \S$ & 15.0 & $0.19 \pm 0.01$ & $0.67 \pm 0.03$ & 0.9956 & $12.9 \pm 0.6$ \\
\hline+ HA $\left(7.4 \mathrm{~g} \mathrm{~kg}^{-1}\right) \S$ & 18.1 & $0.20 \pm 0.02$ & $0.69 \pm 0.07$ & 0.9813 & $11.1 \pm 1.0$ \\
\hline+ FA $\left(1.1 \mathbf{g ~ k g}^{-1}\right) \S$ & 14.7 & $0.15 \pm 0.01$ & $0.47 \pm 0.04$ & 0.9872 & $10.3 \pm 0.5$ \\
\hline
\end{tabular}

$\dagger$ Value \pm SE.

+ Organic carbon-normalized $\boldsymbol{K}_{\mathrm{f}}$ value.

$\S$ Quantity added equivalent to a compost application ratio of $90 \mathrm{Mg} \mathrm{ha}^{-1}$. FA, fulvic acids; HA, humic acids; HoDOM, hydrophobic dissolved organic matter.

the samples can be assumed to be the same as that observed for standards.

\section{Extraction and Residue Analysis for the Degradation in Soils}

The pesticide residue analysis from soil samples always results in co-extraction of OM from soil, which generates a large unresolved peak at the beginning of the chromatogram or a hump in the middle, depending on the mobile phase gradient applied for the separation (Pichon et al., 1996). We found that commonly used analytical techniques for the quantification of triasulfuron in soil (Gennari et al., 2000; Powley and de Bernard, 1998) did not have adequate sensitivity to unambiguously detect and quantify triasulfuron due to the presence of compost and HoDOM, which resulted in a significant increase in the amount of co-extracted interfering OM. For this reason an extraction procedure was designed to reduce the extent of $\mathrm{OM}$ interference: this involved extraction of the herbicide at $\mathrm{pH} 7$ and a two-cartridge, solid-phase extraction (SPE) cleanup step for the isolation of triasulfuron.

Extraction of triasulfuron was performed by shaking $100 \mathrm{~g}$ of soil for $1 \mathrm{~h}$ with $150 \mathrm{~mL}$ extraction solution (methanolphosphate buffer at $\mathrm{pH} 7[2: 1, \mathrm{v} / \mathrm{v}])$ followed by centrifugation at $3500 \times g$ for $20 \mathrm{~min}$. The supernatant was decanted and the procedure repeated, reuniting the supernatants in a roundbottomed flask. The methanol was removed by rotary evaporation and the aqueous extract acidified to $\mathrm{pH} 2.5$ with $2 \mathrm{~mL}$ of glacial acetic acid. Any remaining suspended particles were removed by centrifugation at $10000 \times g$ for $20 \mathrm{~min}$.

Triasulfuron was then extracted from the clear supernatant by SPE. For each extraction procedure, two SPE cartridges were used. The first cartridge was a $6-\mathrm{mL}$ barrel, 500-mg bed, Isolute Strata- $\mathrm{NH}_{2}$, anion exchange resin cartridge (Phenomenex, Torrance, CA). This cartridge removed much of the coextracted OM from the sample. Triasulfuron was not retained by the resin at this $\mathrm{pH}$. The second cartridge was a 6-mL barrel, 100-mg bed, Isolute Strata-X, polymeric SPE cartridge (Phenomenex) that retained the triasulfuron in solution. The procedure used for the extraction steps using SPE involved: (i) conditioning the first cartridge with $5 \mathrm{~mL} 1 \%$ acetic acid in methanol, (ii) washing with $5 \mathrm{~mL}$ of $1 \%$ acetic acid in water, (iii) percolating the sample $\left(10 \mathrm{~mL} \mathrm{~min}^{-1}\right)$ and collecting the eluate, (iv) washing the cartridge with $5 \mathrm{~mL}$ of $1 \%$ acetic acid in water, (v) conditioning the second cartridge with $2 \mathrm{~mL}$ of $1 \%$ acetic acid in methanol, (vi) washing with $2 \mathrm{~mL}$ of $1 \%$ acetic acid in water, (vii) percolating the eluate from the first cartridge $\left(10 \mathrm{~mL} \mathrm{~min}^{-1}\right)$, discarding the eluate, (viii) washing the cartridge with $2 \mathrm{~mL}$ of $1 \%$ acetic acid in water, (ix) drying the cartridge with an air flow for $10 \mathrm{~min}$, (x) desorption of triasulfuron with $3 \mathrm{~mL}$ of $0.1 \%$ acetic acid in hexane-ethyl acetate $(1: 1, \mathrm{v} / \mathrm{v}),(\mathrm{xi})$ evaporation to dryness under a stream of nitrogen, (xii) adding $500 \mu \mathrm{L}$ of acetonitrilewater (1:1) at $\mathrm{pH} 2.5$, (xiii) filtration through a $0.2-\mu \mathrm{m}$ membrane filter, and (xiv) HPLC analysis by injection of $20 \mu \mathrm{L}$ of residual solution.

The average percentage recovery for this method, for a soil spiking level of $54 \mu \mathrm{g}$ a.i. $\mathrm{kg}^{-1}$, was $86.3 \pm 0.3 \%$ for the soil samples, $86.8 \pm 0.9 \%$ for compost-amended samples, and $89.9 \pm 1.6 \%$ for HoDOM-amended samples.

\section{RESULTS AND DISCUSSION Sorption of Triasulfuron to Amended and Nonamended Soils}

The high solubility of triasulfuron in water, especially at $\mathrm{pH}>6$ (at which its anionic form is predominant), suggests that triasulfuron is only weakly adsorbed on soils and may therefore leach down the soil profile. Triasulfuron adsorption isotherms on amended and nonamended Filoncia and Molinaccio soils are shown in Fig. 1, and the corresponding Freundlich sorption coefficients $\left(K_{\mathrm{f}}\right.$ and $1 / n)$, obtained by fitting the sorption data to the Freundlich equation, are reported in Table 3 . The analysis of the $1 / n$ sorption coefficients indicates isotherm nonlinearity $(1 / n<1)$ and concentration-dependent triasulfuron solid-solution distribution in all isotherms ob-

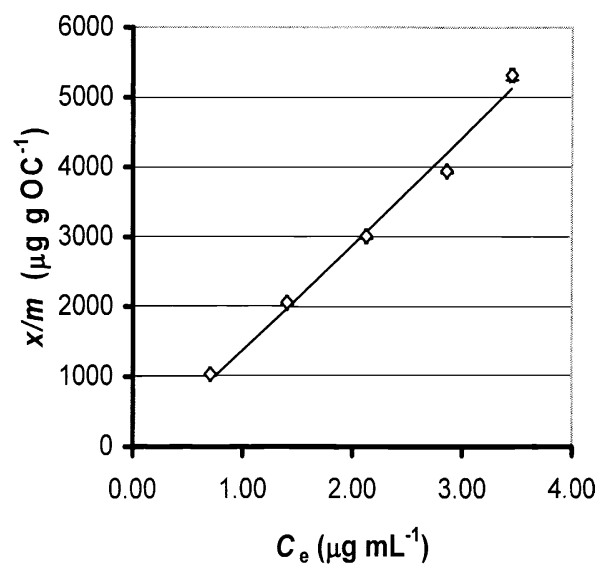

Fig. 2. Isotherm for the association of triasulfuron to hydrophobic dissolved organic matter (HoDOM) from municipal soil waste compost. Error bars represent $\mathrm{SE}<$ symbol size. 
Table 4. Hydrolysis of triasulfuron in aqueous buffer solutions in the presence and absence of fulvic acids (FA), humic acids (HA), and hydrophobic dissolved organic matter (HoDOM) at $20^{\circ} \mathrm{C}$.

\begin{tabular}{|c|c|c|c|}
\hline Solution & $k \times 10^{-3} \dagger$ & $t_{1 / 2} \dagger$ & $r^{2}$ \\
\hline & $\mathbf{d}^{-1}$ & $\begin{array}{c}\text { d } \\
\text { pH } 4.5\end{array}$ & dimensionless \\
\hline $\begin{array}{l}\text { Water } \\
\text { Water + HA } \\
\text { Water + FA } \\
\text { Water + HoDOM }\end{array}$ & $\begin{array}{l}36 \pm 1 \\
40 \pm 1 \\
43 \pm 1 \\
44 \pm 1\end{array}$ & $\begin{array}{r}19.1 \pm 0.7 \\
17.1 \pm 0.3 \\
16.2 \pm 0.3 \\
15.8 \pm 0.3 \\
\text { pH } 7.0\end{array}$ & $\begin{array}{l}0.9895 \\
0.9974 \\
0.9973 \\
0.9974\end{array}$ \\
\hline $\begin{array}{l}\text { Water } \\
\text { Water + HA } \\
\text { Water + FA } \\
\text { Water + HoDOM }\end{array}$ & $\begin{array}{l}\mathbf{8} \pm \mathbf{1} \\
\mathbf{8} \pm \mathbf{1} \\
\mathbf{8} \pm \mathbf{1} \\
\mathbf{9} \pm \mathbf{1}\end{array}$ & $\begin{array}{l}82.2 \pm 2.9 \% \\
86.4 \pm 3.1 \% \\
89.2 \pm 3.0 \% \\
76.8 \pm 3.8 \%\end{array}$ & $\begin{array}{l}0.9895 \\
0.9897 \\
0.9921 \\
0.9821\end{array}$ \\
\hline
\end{tabular}

$\dagger$ Value $\pm 95 \%$ confidence interval.

$\uparrow$ Extrapolated by regression curve.

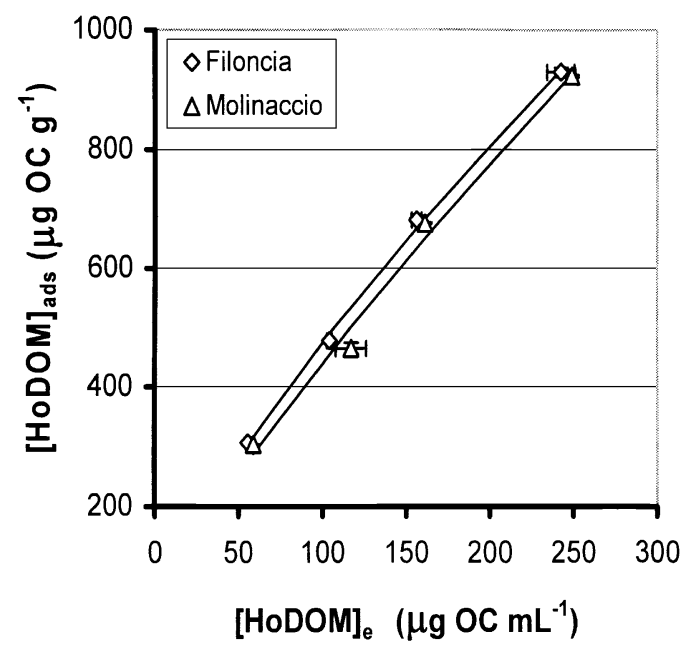

Fig. 3. Representative isotherms for the sorption of hydrophobic dissolved organic matter (HoDOM) to two soils. Error bars represent SE.

tained. The heterogeneous composition and structure of soil and compost substances, as well as the diversity of adsorption mechanisms, contribute to nonlinear sorption isotherms as commonly reported in literature (Cox et al., 2001; Gennari and Gessa, 1997; Gunasekara and Xing, 2003; Senesi et al., 1997). The nonlinear isotherms obtained in this study indicate that the adsorbent (the amended or nonamended soil) has a moderately lower affinity for the solute (triasulfuron) at higher final concentrations, which probably occurs due to the saturation of the adsorption sites. Within the experimental concentration range used, no limiting adsorption was observed for triasulfuron to the amended or nonamended soils. This result implies that our samples had adsorbent surfaces that were never completely saturated by triasulfuron. For both soils used, the degree of nonlinearity decreased with the higher compost amendment and with treatment with HA and HoDOM.

Nonlinear isotherms are also confirmed with changes in the sorption coefficients over the experimental concentration $(C)$ range used (data not shown). The concentration-dependent sorption coefficients, calculated from $K_{\mathrm{f}}$ and $1 / n$ values as described by Chen et al.
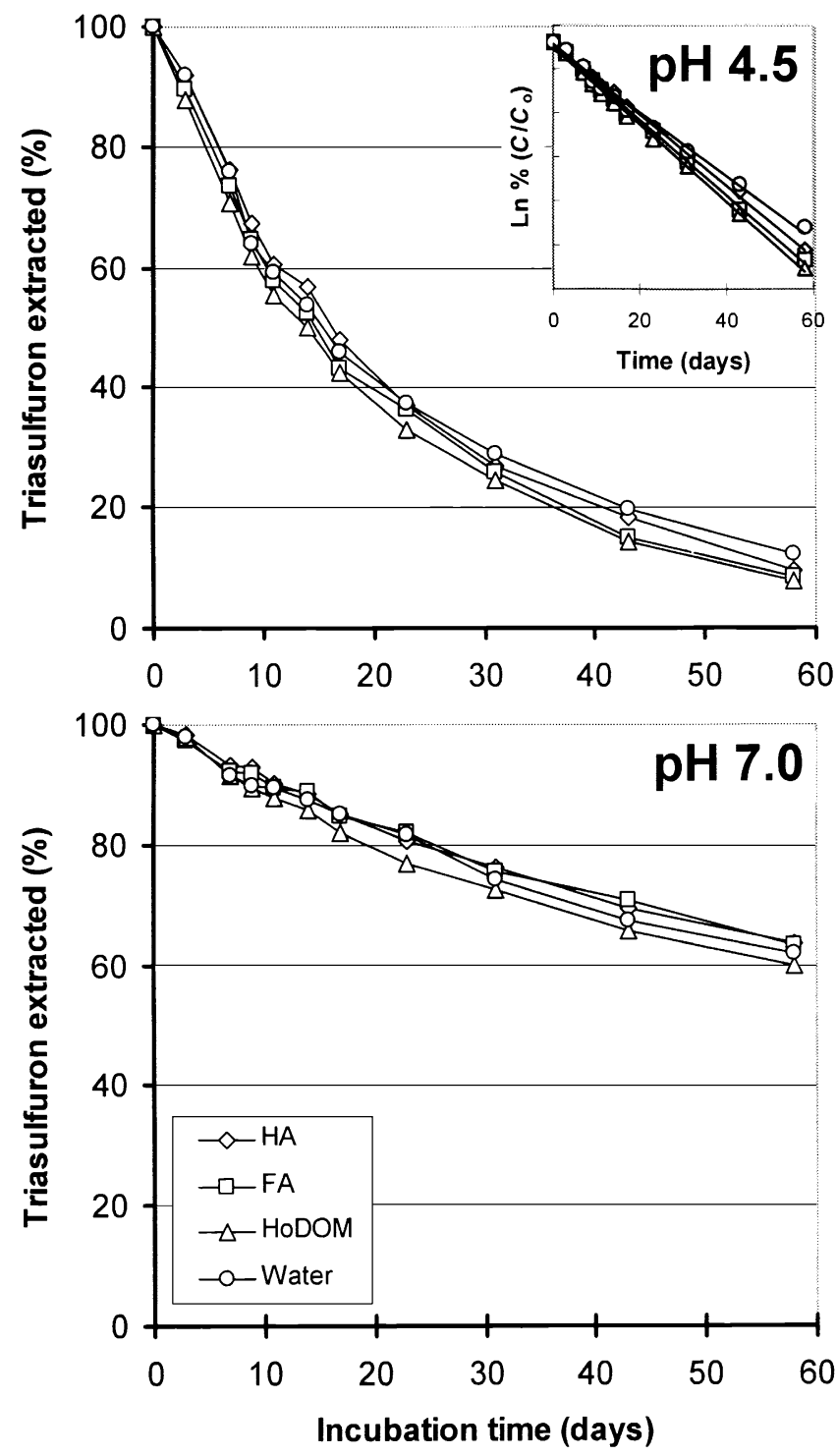

Fig. 4. Comparative hydrolytic degradation pattern of triasulfuron in water at different $\mathrm{pH}$ values, in the presence and absence of humic acids (HA), fulvic acids (FA), and hydrophobic dissolved organic matter (HoDOM).

(1999), facilitate comparison between isotherms due to nonlinearity. The low $K_{\mathrm{f}}$ values for herbicide adsorption to the two soils confirm the preference triasulfuron shows to remain in solution. The $K_{\mathrm{f}}$ value was higher for the Molinaccio soil with the higher OM content, even though the two soils were both low in organic carbon content. Since the $K_{\mathrm{oc}}$ values are similar for both soils over the experimental $C$ range, the differences in $K_{\mathrm{f}}$ for the two soils are explained by their differences in OM content. The addition of compost to soil increases the adsorption of triasulfuron significantly only when applied at a dose of $90 \mathrm{Mg} \mathrm{ha}^{-1}$. This increase could be related to the addition of OM to the soil, thus increasing the sorption sites available for adsorption. This confirms the role of soil OM as the primary adsorbing component for triasulfuron in soil. Results in Table 3 show that different organic matter has different sorption efficacy. The decrease in $K_{\text {oc }}$ values with increasing compost ap- 


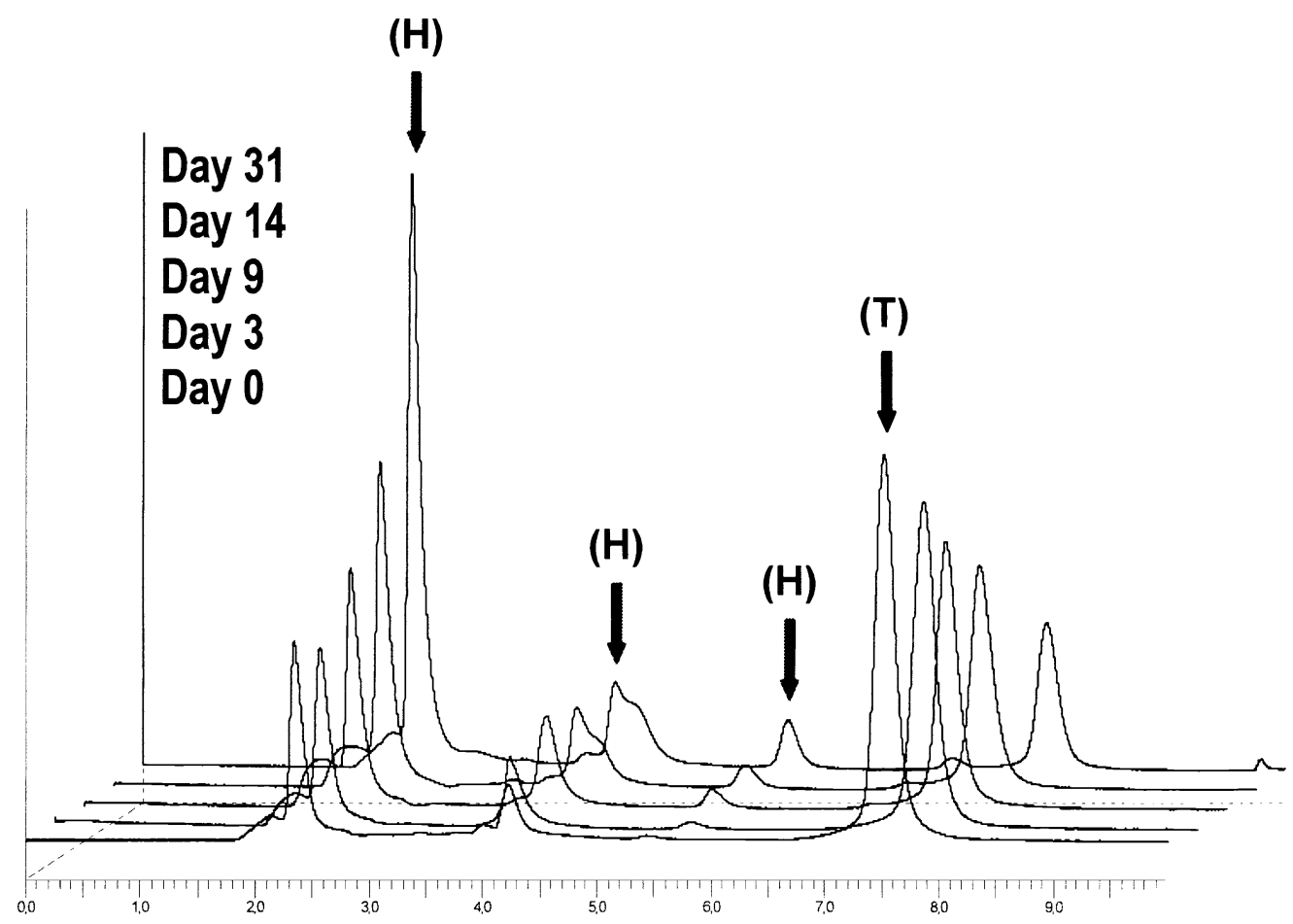

Fig. 5. Chromatograms of triasulfuron and simultaneous appearance of hydrolytic products on different days from acid hydrolysis aqueous experiment at $\mathrm{pH}$ 4.5. The arrows indicate retention times for triasulfuron $(\mathrm{T})$ and hydrolysates $(\mathrm{H})$.

plication for both soils suggests that the increase in triasulfuron adsorption depends not only on the quantity but also on the nature of OC added. This supports the hypothesis that triasulfuron is selectively adsorbed by particular OM fractions present in compost. Addition of the HA and HoDOM fractions extracted from compost to the two soils resulted in the most significant increase in both $K_{\mathrm{f}}$ and $K_{\mathrm{oc}}$ values (Table 3 ) over the experimental $C$ range.

\section{Triasulfuron-Dissolved Organic Matter and Dissolved Organic Matter-Soil Interactions}

The increased triasulfuron adsorption in soil-HoDOM combinations could be due to the coupled effect of triasulfuron adsorption to HoDOM and HoDOM sorption to soil. The relative importance of the interactions in solution between triasulfuron and compost HoDOM was evaluated by equilibrium dialysis. The isotherm obtained (Fig. 2) had a $K_{\mathrm{f}}$ value of $1381 \pm 123 \mathrm{~mL} \mathrm{~g}^{-1} \mathrm{OC}$ and a $1 / n$ value of $1.06 \pm 0.08$, showing that there was a great affinity between the pesticide and the hydrophobic fraction of compost DOM. The $1 / n$ sorption coefficient indicates a concentration-independent distribution ratio for triasulfuron between free and HoDOM-sorbed states.

Sorption isotherms of HoDOM extracted from MWC with Filoncia and Molinaccio soils are shown in Fig. 3. The respective Freundlich $K_{\mathrm{f}}$ values for the two soils $\left(K_{\text {HoDOM-soil }}\right)$ were $14.2 \pm 1.8$ and $10.4 \pm 3.7 \mathrm{~mL} \mathrm{~g}^{-1}$. The difference between the HoDOM adsorption onto the two soils is not significant and the percentage adsorption of dissolved organic carbon was about $80 \%$ for both soils. However, these values support the hypothesis that DOM applied to the soils will undergo sorption reac- tions with the soil and in the sorbed state, will serve to increase the adsorption capacity of the soil for hydrophobic chemicals.

\section{Hydrolytic Degradation of Triasulfuron}

To study the effects of compost-derived OM on the rate of hydrolysis of triasulfuron, aqueous buffered $(\mathrm{pH}$ 4.5 and 7.0) solutions containing HA, FA, and HoDOM were used. The rate of hydrolytic degradation at $20^{\circ} \mathrm{C}$ followed first-order kinetics with rate constant $(k)$ and $r^{2}$ values as shown in Table 4. Degradation was slowest under neutral conditions ( $\mathrm{pH}$ 7.0) with an average extrapolated half-life $\left(t_{1 / 2}\right)$ of $84 \mathrm{~d}$ (Fig. 4). At a pH value of 4.5 the rate of degradation in all test samples increased approximately fivefold with an average half-life of $17 \mathrm{~d}$ and a $90.5 \%$ reduction in the triasulfuron concentration after $58 \mathrm{~d}$. The lower hydrolysis rate constants for the buffered solutions at $\mathrm{pH} 7.0$ show that triasulfuron is relatively stable at this $\mathrm{pH}$ and less likely to be degraded abiotically than in more acidic solutions. Figure 5 shows the HPLC chromatograms of triasulfuron and the simultaneous appearance of hydrolytic products on different days, obtained from the acid hydrolysis experiment at $\mathrm{pH}$ 4.5. Similar results have been reported for other sulfonylurea herbicides. The acid-catalyzed cleavage of the sulfonylurea bridge to yield the corresponding sulfonamide and heterocyclic amine, which occurs with a faster rate at lower $\mathrm{pH}$ values, has been demonstrated to be the primary pathway of triasulfuron degradation by various authors (Braschi et al., 1997; Sarmah et al., 2000). Moreover, the results obtained in this work show that the outstanding $\mathrm{pH}$ dependence of triasulfuron hydrolysis is only minimally affected by the presence of 
$\mathrm{OM}$ in solution. The observed hydrolysis rates at $\mathrm{pH}$ 7.0 in the presence of $\mathrm{OM}$ were not statistically different $(P=0.05)$ from the rate in buffered water at the same $\mathrm{pH}$. On the other hand, the presence of $\mathrm{OM}$ in the aqueous buffered solutions at $\mathrm{pH} 4.5$ only slightly affected the rate of hydrolytic degradation. However, the rates of degradation in the presence of the different $\mathrm{OM}$ fractions extracted from compost were statistically different $(P=0.01)$ from the rate in water at this $\mathrm{pH}$ and half-lives decreased in the order water $>\mathrm{HA}>$ FA $>$ HoDOM. These results, together with the previous results obtained for the adsorption of triasulfuron to amended soil and particularly to HoDOM in solution, seem to suggest that the adsorption of the pesticide to $\mathrm{OM}$ tends to increase its potential for abiotic degradation. One possible explanation for this is that adsorption of triasulfuron to compost HoDOM occurs through proton transfer from the carboxyl groups to the sulfonylurea $\mathrm{N}$ atoms, with possible formation of ionic bonds between negatively charged $\mathrm{OM}$ and positively charged triasulfuron. This proton transfer could facilitate the acid-catalyzed hydrolytic degradation reaction.

\section{Degradation of Triasulfuron in Amended and Nonamended Soils}

The kinetics of triasulfuron degradation was monitored in the two soils nonamended, amended with compost $\left(30 \mathrm{Mg} \mathrm{ha}^{-1}\right)$, and treated with HoDOM (Fig. 6). Under laboratory conditions, triasulfuron content decreased with time over $60 \mathrm{~d}$ in all nonamended, amended, and treated soil samples. In all cases the triasulfuron degradation was rapid in the first $20 \mathrm{~d}$ but subsequently became slower. This deviation of soil degradation kinetics from first-order kinetics and the exhibition of twostage degradation kinetics has been observed for other sulfonylureas (Morrica et al., 2002). Some authors explain this two-stage model through a decreased availability of sulfonylureas to soil microbes as a result of pesticide adsorption. The second, slower, decline stage is probably due to chemical hydrolysis, the rate of which is generally slower than that due to microbial degradation (Morrica et al., 2001, 2002).

Based on the first-order model, the estimated values of $t_{1 / 2}$ in nonamended, amended, and treated soils ranged between 40 and $75 \mathrm{~d}$ for both soils investigated. These results disagree with the experimental data (Fig. 6), from which it appears that the half-lives are clearly less than $40 \mathrm{~d}$. The best fit was obtained by considering the degradation process occurring in two successive first-order steps, as was suggested from the kinetic profile (Fig. 6). Rate constants and half-lives for the degradation of triasulfuron in the nonamended, amended, and treated soil samples during the first $25 \mathrm{~d}$, corresponding to the first stage, are reported in Table 5. For both soils, minor but statistically significant differences in the rate constants and half-lives resulted from compost amendment and treatment with HoDOM. The rate of degradation decreased in the order soil $>$ soil amended with compost $\geq$ soil treated with HoDOM. These results show that the fast biotic pesticide degradation in the first $25 \mathrm{~d}$
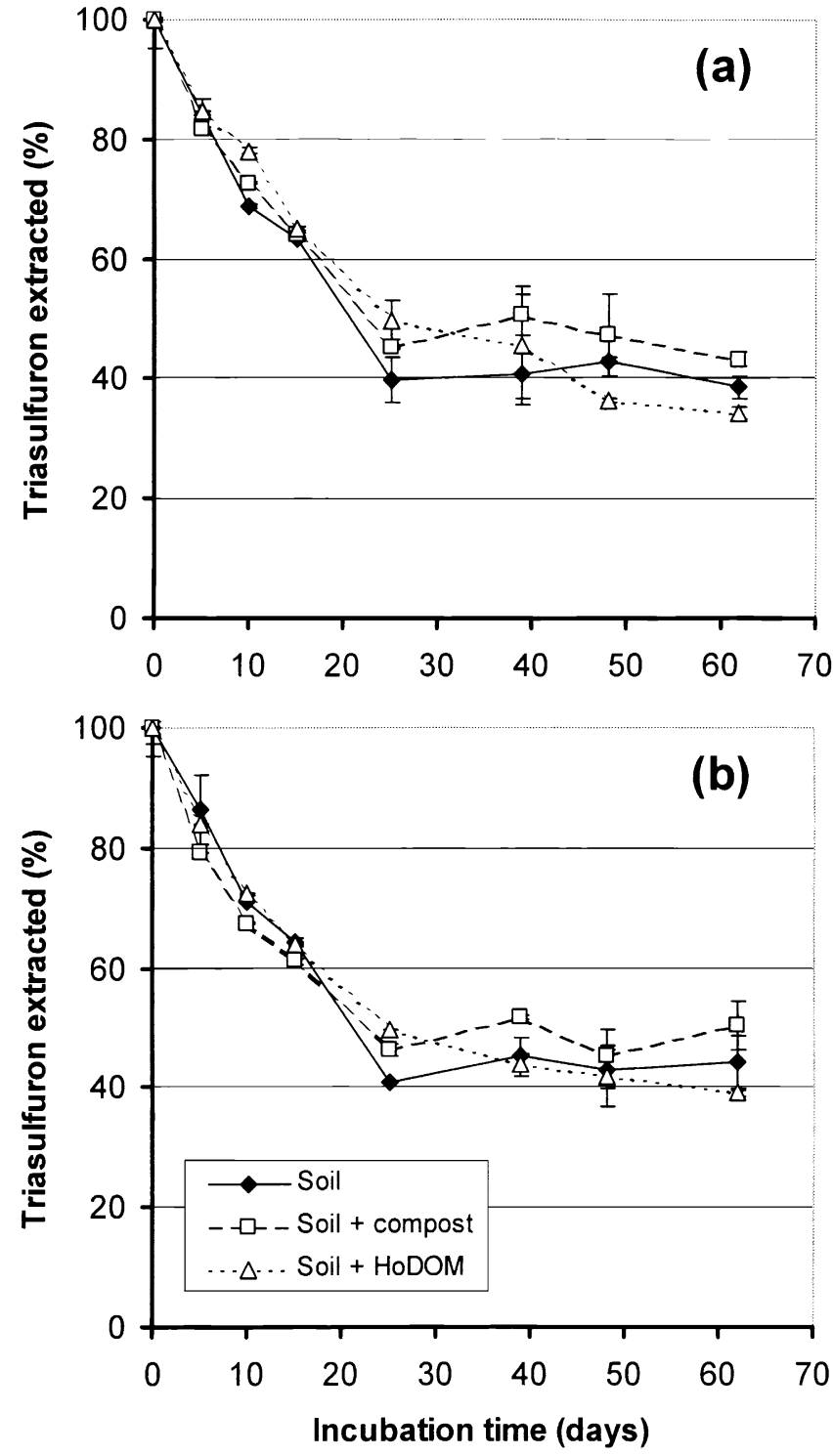

Fig. 6. Kinetics of triasulfuron degradation in amended and nonamended (a) Filoncia and (b) Molinaccio soils. Error bars represent $95 \%$ confidence interval.

of incubation is somewhat inhibited by the presence of compost or HoDOM, suggesting that the adsorption phenomena reported previously protect triasulfuron from microbial action.

In all nonamended, amended and treated soil samples, the rate of degradation was clearly reduced after $25 \mathrm{~d}$ of incubation, approaching rates similar to those

Table 5. Degradation of triasulfuron in amended and nonamended soil during the first $25 \mathrm{~d}$.

\begin{tabular}{lccc}
\hline Soil & $\boldsymbol{k} \times \mathbf{1 0}^{-3} \dagger$ & $\boldsymbol{t}_{1 / 2} \dagger$ & $\boldsymbol{r}^{\mathbf{2}}$ \\
\hline & $\mathbf{d}^{-\mathbf{1}}$ & $\mathrm{d}$ & dimensionless \\
Filoncia loam & $\mathbf{3 6} \pm \mathbf{2}$ & $\mathbf{1 9 . 3} \pm \mathbf{1 . 4}$ & $\mathbf{0 . 9 8 6 0}$ \\
+ compost & $\mathbf{3 1} \pm \mathbf{1}$ & $\mathbf{2 2 . 5} \pm \mathbf{1 . 1}$ & $\mathbf{0 . 9 9 3 6}$ \\
+ HoDOM $\dagger$ & $\mathbf{2 8} \pm \mathbf{1}$ & $\mathbf{2 5 . 0} \pm \mathbf{1 . 2}$ & $\mathbf{0 . 9 9 3 7}$ \\
Molinaccio clay loam & $\mathbf{3 5} \pm \mathbf{2}$ & $\mathbf{1 9 . 6} \pm \mathbf{1 . 4}$ & $\mathbf{0 . 9 8 6 3}$ \\
+ compost & $\mathbf{3 0} \pm \mathbf{2}$ & $\mathbf{2 3 . 4} \pm \mathbf{2 . 0}$ & $\mathbf{0 . 9 8 1 1}$ \\
+ HoDOM & $\mathbf{2 8} \pm \mathbf{1}$ & $\mathbf{2 5 . 2} \pm \mathbf{1 . 2}$ & $\mathbf{0 . 9 9 4 0}$ \\
\hline
\end{tabular}

$\dagger$ Value $\pm 95 \%$ confidence interval.

† Hydrophobic dissolved organic matter. 
obtained for hydrolysis. It was not possible to calculate half-lives for the second stage since the results obtained during this stage were few and not always significantly different.

\section{CONCLUSIONS}

The incorporation of OM to soil by MWC amendment influences triasulfuron adsorption behavior in soil. The results of this work showed that the overall effect of compost addition to soil on the distribution of triasulfuron between the liquid and solid phase was an increase in sorption due to the high sorption capacity of the added OM. Dissolved organic matter applied to the soil through soil amendment with MWC will undergo sorption reactions with the soil, and in the sorbed state will also serve to increase the adsorption capacity of the soil for organic pesticide molecules.

The rate of hydrolysis of triasulfuron in solution was significantly higher at acidic $\mathrm{pH}$ and the presence of OM fractions extracted from compost also slightly increased the rate of hydrolysis. The affinity triasulfuron showed toward OM suggests that adsorption increases its potential for abiotic degradation. The rate of degradation of triasulfuron in amended and nonamended soils has been explained by two-stage degradation kinetics: an initial stage during which triasulfuron degradation occurred rapidly possibly due to microbial degradation and a subsequent stage characterized by a decrease in the rate of degradation during which chemical hydrolysis probably dominates. During the initial stage, triasulfuron degradation was slightly hindered by the presence of compost and HoDOM, suggesting that adsorption to the humic-like substances and DOM present in these additives reduces its availability to microorganisms.

\section{ACKNOWLEDGMENTS}

This work was partially supported by the Leonardo da Vinci program of the European Commission as part of the project ISDEPS 2002.

\section{REFERENCES}

Barriuso, E., S. Houot, and C. Serra-Wittling. 1997. Influence of compost addition to soil on the behaviour of herbicides. Pestic. Sci. 49: 65-75.

Braschi, I., L. Calamai, M.A. Cremonini, P. Fusi, C. Gessa, O. Pantani, and A. Pusino. 1997. Kinetics and hydrolysis mechanism of triasulfuron. J. Agric. Food Chem. 45:4495-4499.

Businelli, D., G. Gigliotti, and P.L. Giusquiani. 1998. The fate of terbuthylazine in a clay soil treated with pig slurry. Fresenius Environ. Bull. 7:729-736.

Celis, R., E. Barriuso, and S. Houot. 1998a. Effect of liquid sewage sludge addition on atrazine sorption and desorption by soil. Chemosphere 37:1091-1107.

Celis, R., E. Barriuso, and S. Houot. 1998b. Sorption and desorption of atrazine by sludge-amended soil: Dissolved organic matter effects. J. Environ. Qual. 27:1348-1356.

Chen, Z., B. Xing, and W.B. McGill. 1999. A unified sorption variable for environmental applications of the Freundlich equation. J. Environ. Qual. 28:1422-1428.

Cox, L., A. Cecchi, R. Celis, M.C. Hermosín, W.C. Koskinen, and J. Cornejo. 2001. Effect of exogenous carbon on movement of simazine and 2,4-D in soils. Soil Sci. Soc. Am. J. 65:1688-1695.

Dinelli, G., A. Vicari, and C. Accinelli. 1998. Degradation and side effects of three sulfonylurea herbicides in soil. J. Environ. Qual. 27: 1459-1464.

Gennari, M., L. Ferraris, M. Nègre, and A. Cignetti. 2000. Liquid chromatographic determination of triasulfuron in soil. J. AOAC Int. 83:1076-1081.

Gennari, M., and C. Gessa. 1997. Evaluation of soil adsorption-desorption capacity for the assessment of pesticide bioavailability. In P. Baveye, J.C. Block, and V.V. Goncharuk (ed.) Bioavailability of organic xenobiotics in the environment. Practical consequences for the environment. Proc. of the NATO Advanced Study Inst., Prague, Czech Republic. 18-29 Aug. 1997.

Gigliotti, G., D. Businelli, and P.L. Giusquiani. 1999. Composition changes of soil humus after massive application of urban waste compost: A comparison between FT-IR spectroscopy and humification parameters. Nutr. Cycling Agroecosyst. 55:23-28.

Gigliotti, G., K. Kaiser, G. Guggenberger, and L. Haumaier. 2002. Differences in the chemical composition of dissolved organic matter from waste material of different sources. Biol. Fertil. Soils 36:321329.

Gigliotti, G., and D. Solomon. 2000. Influence of organic refuses addition to soil on the behaviour of terbuthylazine. p. 677-680. In Book of abstracts. 10th Int. Meeting of the IHSS, Toulouse, France. 24-28 July 2000.

Giusquiani, P.L., M. Pagliai, G. Gigliotti, D. Businelli, and A. Benetti. 1995. Urban waste compost: Effects on physical, chemical and biochemical soil properties. J. Environ. Qual. 24:175-182.

Gunasekara, A.S., and B. Xing. 2003. Sorption and desorption of naphthalene by soil organic matter: Importance of aromatic and aliphatic components. J. Environ. Qual. 32:240-246.

Huang, X., and L.S. Lee. 2001. Effects of dissolved organic matter from animal waste effluent on chlorpyrifos sorption by soils. J. Environ. Qual. 30:1258-1265.

Moore, T.R. 1985. The spectrophotometric determination of dissolved organic carbon in peat waters. Soil Sci. Soc. Am. J. 49:1590-1592.

Moorman, T.B., J.K. Cowan, E.L. Arthur, and J.R. Coats. 2001. Organic amendments to enhance herbicide biodegradation in contaminated soils. Biol. Fertil. Soils 33:541-545.

Morrica, P., P. Fidente, S. Seccia, and M. Ventriglia. 2002. Degradation of imazosulfuron in different soils-HPLC determination. Biomed. Chromatogr. 16:489-494.

Morrica, P., A. Giordano, S. Seccia, F. Ungaro, and M. Ventriglia. 2001. Degradation of imazosulfuron in soil. Pest Manage. Sci. 57:360-365.

Pichon, V., C. Cau Dit Coumes, L. Chen, S. Guenu, and M.-C. Hennion. 1996. Simple removal of humic and fulvic acid interferences using polymeric sorbents for the simultaneous solid-phase extraction of polar acidic, neutral and basic pesticides. J. Chromatogr. A 737:25-33.

Pizzigallo, M.D.R., R. Mininni, and P. Ruggiero. 2001. Adsorption of triasulfuron on different soils and humic acids. Fresenius Environ. Bull. 10:221-225.

Powley, C.R., and P.A. de Bernard. 1998. Screening method for nine sulfonylurea herbicides in soil and water by liquid chromatography with ultraviolet detection. J. Agric. Food Chem. 46:514-519.

Sarmah, A.K., R.S. Kookana, M.J. Duffy, A.M. Alston, and B.D Harch. 2000. Hydrolysis of triasulfuron, metsulfuron-methyl and chlorsulfuron in alkaline soil and aqueous solutions. Pest Manage. Sci. 56:463-471

Senesi, A., P. La Cava, and T.M. Miano. 1997. Adsorption of imazethapyr to amended and nonamended soils and humic acids. J. Environ. Qual. 26:1264-1270.

Seol, Y., and L.S. Lee. 2000. Effect of dissolved organic matter in treated effluents on sorption of atrazine and prometryn by soils. Soil Sci. Soc. Am. J. 64:1976-1983. 